\title{
Encarceramento de mulheres na Penitenciária Modulada de Ijuí/RS: o caso de uma instituição prisional (masculinamente) mista no contexto da pandemia de Covid-19
}

\author{
Incarceration of women in the modulated penitentiary of Ijuí / RS: the case of a (masculinely) \\ mixed prison institution in the context of the Covid-19 \\ Encarcelamiento de mujeres en la Penitenciaría Modulada de Ijuí / RS: el caso de una institución \\ carcelaria (masculinamente) mista en el contexto de la pandemia del Covid-19
}

Recebido: 00/11/2021 | Revisado: 00/12/2021 | Aceito: 13/12/2021 | Publicado: 20/12/2021

\author{
Camila Belinaso \\ ORCID: https://orcid.org/0000-0002-2766-1672 \\ Universidade La Salle, Brasil \\ E-mail: camilabelinaso@gmail.com \\ Salo de Carvalho \\ ORCID: https://orcid.org/0000-0002-2006-9916 \\ Universidade La Salle, Brasil \\ Universidade Federal do Rio de Janeiro, Brasil \\ E-mail: salo.carvalho@uol.com.br
}

\begin{abstract}
Resumo
Os dados oficiais do Departamento Penitenciário brasileiro (DEPEN) demonstram que as prisões brasileiras possuem a quarta maior população feminina carcerária do mundo, em um contexto de considerável déficit de vagas. Com a decretação da Pandemia de Covid-19, o poder público estabeleceu critérios para desencarceramento através da Recomendação $\mathrm{n}^{\circ}$ 62, de 17 de março de 2020, editada pelo Conselho Nacional de Justiça (CNJ). Neste cenário, o estudo tem como objetivo central analisar a condição de sobrecarga punitiva mediante a verificação da (in)eficácia dessa Recomendação. Desde as criminologias feminista e crítica, no marco do abolicionismo penal, é realizada pesquisa de campo na Penitenciária Modulada Estadual de Ijuí (PMI), uma das instituições carcerárias que compõem

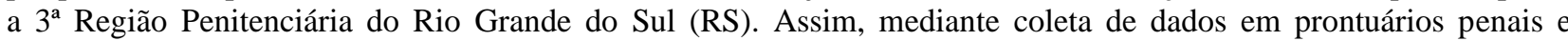
entrevistas semiestruturadas, o estudo objetiva, especificamente, (a) verificar o nível de efetividade das regras limitativas de manutenção e decretação de prisões no contexto da pandemia; e (b) identificar as sobrecargas punitivas que sofrem as mulheres privadas de liberdade, ou seja, o maior nível de restrições de direitos impostos às mulheres em comparação com os direitos concedidos aos homens presos no mesmo ambiente, notadamente por ser a instituição prisional analisada (masculinamente) mista. A título de conclusão tem-se que a permanência nas condições ilegais de encarceramento apesar da crise está legitimada por decisões judiciais e administrativas.
\end{abstract}

Palavras-chave: Criminologia crítica; Criminologia feminista; Encarceramento feminino; Pandemia de Covid-19; Prisão.

\begin{abstract}
Official data from the Brazilian National Prison Department (DEPEN) shows that Brazilian prison facilities have the fourth highest female incarcerated population in the world and intense overcrowding. With the Covid-19 pandemic being declared, the public authorities established criteria for the release by Recommendation No. 62, of March 17, 2020, edited by the National Council of Justice (CNJ). In this scenario, the study aims to analyze the condition of punitive overload by verifying the (in) effectiveness of this recommendation. From feminist and critical criminologies, within the framework of penal abolitionism, field research is carried out at the State Modulated Penitentiary of Ijuí (PMI), one of the prison institutions that make up the 3rd Penitentiary Region of Rio Grande do Sul (RS). Thus, by collecting data from criminal records and semi-structured interviews, the study specifically aims to (a) verify the level of effectiveness of the limiting rules for maintaining and decreeing prisons in the context of the pandemic; and (b) to identify the punitive burdens suffered by women deprived of their liberty, that is, the higher level of rights restrictions imposed on women compared to the rights granted to men imprisoned in the same environment, notably because the prison institution is analyzed ( masculinely) mixed. As a conclusion, it remains that staying in illegal conditions of incarceration despite the crisis is legitimized by judicial and administrative decisions.
\end{abstract}

Keywords: Critical criminology; Feminist criminology; Female incarceration; Covid-19 Pandemic; Prisons.

\section{Resumen}

Los datos oficiales del Departamento Penitenciario de Brasil (DEPEN) muestran que las cárceles brasileñas tienen la cuarta población carcelaria femenina más grande del mundo, en un contexto de considerable falta de vacantes. Con la 
promulgación de la Pandemia Covid-19, las autoridades públicas establecieron criterios para el desencarcelamiento mediante la Recomendación No. 62, de 17 de marzo de 2020, editada por el Consejo Nacional de Justicia (CNJ). En este escenario, el estudio tiene como objetivo analizar la condición de sobrecarga punitiva verificando la (in) efectividad de esta Recomendación. Desde las criminologías feminista y crítica, en el marco del abolicionismo penal, la investigación de campo se realiza en la Penitenciaría Estatal Modulada de Ijuí (PMI), una de las instituciones carcelarias que conforman la $3^{\mathrm{a}}$ Región Penitenciaria de Rio Grande do Sul (RS). Así, a través de datos de antecedentes penales y entrevistas semiestructuradas, el estudio tiene como objetivo específico (a) verificar el nivel de efectividad de las reglas limitantes para el mantenimiento y decreto de prisiones en el contexto de la pandemia; y (b) identificar las cargas punitivas que sufren las mujeres privadas de libertad, es decir, el mayor nivel de restricciones de derechos que se les impone a las mujeres en comparación con los derechos otorgados a los hombres presos en el mismo entorno, en particular porque se analiza la institución penitenciaria ( masculina) adaptada al femenino. Como conclusión, queda que permanecer en condiciones ilegales de encarcelamiento a pesar de la crisis está legitimada por decisiones judiciales y administrativas.

Palabras clave: Criminología crítica; Criminología feminista; Encarcelamiento de mujeres; Pandemia de Covid-19; Prisión.

\section{Introdução}

O primeiro caso de Covid-19 no Brasil ocorreu no dia 26 de fevereiro de 2020 e logo depois os índices de contaminação divulgados pelo Ministério da Saúde, pelas Secretarias de Saúde de estados e municípios aumentaram consideravelmente. Nesse contexto, o olhar ao sistema prisional teve relevância a partir da Recomendação $\mathrm{n}^{\circ} 62$, de 17 de março de 2020, do Conselho Nacional de Justiça (CNJ), que trouxe orientações ao poder judiciário quanto às medidas preventivas às contaminações em massa nos sistemas de privação de liberdade.

Desde a Recomendação do CNJ e a realidade do encarceramento em massa de mulheres no Brasil, o estudo ocorre na Penitenciária Modulada Estadual de Ijuí (PMI), localizada no noroeste do estado do Rio Grande do Sul (RS). Trata-se de uma instituição prisional masculina adaptada ao encarceramento feminino há quase 20 anos. Essa conformação faz com que a PMI seja intitulada de masculinamente mista, pois sobrepõe ao feminino uma orientação androcêntrica nas práticas e nas dinâmicas carcerárias (Colares \& Chies, 2010). Referido acúmulo, por sua vez, compõe o conceito de sobrecarga de punição, central ao presente estudo, pois abrange situação na qual as mulheres que infringem as leis são duplamente condenadas legalmente, através de um processo criminal e, socialmente, pois consideradas biológica e sexualmente anormais (Lemgruber, 1983).

Assim, com o objetivo de analisar se a pandemia de Covid-19 gerou um aumento da sobrecarga de punição, o estudo se insere num movimento de desburocratização da produção de conhecimento e de deslegitimação do sistema penal a partir da escuta de agentes públicos que o compõem e de mulheres em situação de cárcere. Logo se pretende somar ao movimento que se contrapõe ao ideal social que mantém o lugar degradado como destino do feminino (Federici, 2017).

A construção do estudo está ancorada à criminologia crítica e feminista, no marco do abolicionismo penal, e se vincula à discussão sobre os processos seletivos de criminalização das mulheres para (re)conhecer as opressões que as tornam vulneráveis e precarizadas até serem empurradas à criminalização e ao aprisionamento. Isso porque nem o cárcere nem o encarceramento estão limitados a uma instituição dedicada à execução da pena de privação de liberdade (Borges, 2019).

Assim sendo, a pesquisa aborda dois pontos: primeiro, demonstrar o nível de (in)eficácia das regras limitativas de manutenção e decretação de prisões no contexto da pandemia e, segundo, identificar a condição inerente ao encarceramento de mulheres, ou seja, as sobrecargas punitivas antes e durante a pandemia. E, ao final, demonstrar se a permanência nas condições ilegais de encarceramento apesar da crise está legitimada por decisões judiciais e administrativas.

\section{Método e Metodologias}

O estudo está ancorado no método materialista histórico-dialético, comum à teoria crítica da Escola de Frankfurt, à criminologia crítica (radical) brasileira e ao feminismo negro abolicionista. Assim, tem em Angela Davis a congregação dos 
eixos das bases epistemológicas críticas "a partir do alinhamento da crítica econômica com a de gênero e à racial" (Weigert \& Carvalho, 2019, p. 1803). Em resumo, as formulações de Davis contemplam dois pontos primordiais ao estudo: (i) o entendimento da interseccionalidade de gênero, raça e classe como relações sociais estruturantes e (ii) a proposição de combinar macro e microprocessos (subjetividades) a fim de avançar no projeto de transformação social. Portanto parte da aparência, do padrão, do superficial em busca da essência, do não dito pela organização social que nos constitui para a construção de uma nova sociedade.

Essas consideraç̃oes vão ao encontro do termo interseccionalidade como categoria analítica que abrange gênero, raça e classe para a compreensão da sociedade. Nesse quadro, a reflexão é necessária para perceber que entre essas categorias existem relações que são mútuas e outras que são cruzadas. A inexistência de hierarquias não é o mesmo que universalizar essas categorias ("todas as vidas importam”), uma vez que "ao longo de grande parte da história, a própria categoria 'ser humano' não abarcou pessoas negras e minorias étnicas" (Davis, 2018, p. 107). Por isso, a interseccionalidade transcende o discurso de uma luta meramente indenitária para um novo modelo de sociedade (Ribeiro, 2017).

$\mathrm{O}$ aporte teórico interseccional permite um olhar às funções declaradas latentes do sistema penal mediante uma análise interpretativa (lupa criminológica) que serve para identificar suas contradições entre as promessas humanitárias e as exigências reguladoras. Serve também para denunciar a insistência por uma pretensão entre regulação e emancipação aspirada por uma máxima positivista de "ordem e progresso" que nunca será conquistada (Andrade, 2009, p.174.). Logo atua na perspectiva de uma criminologia atenta à realidade em sua totalidade, contextos de tempo e espaço, para afrontar a racionalidade positivista em busca de propostas libertadoras (Aniyar de Castro, 2005, p. 30).

Definido o método e a perspectiva de análise, são utilizadas, numa dimensão de complementariedade, as metodologias de análise documental dos relatórios de informações das 40 mulheres que se encontravam em situação de cárcere na PMI (dados quantitativos) em 13/12/2019, e de entrevistas semiestruturadas (dados qualitativos) realizadas no período entre 27/05/2020 a 10/06/2020. A pesquisa quantitativa partiu da análise dos relatórios individuais gerados no sistema de estatística do Departamento Penitenciário brasileiro (DEPEN), com seleção de dados como regime/tipo de recolhimento, última entrada, e perfil sociodemográfico. Já a pesquisa qualitativa partiu da realização de entrevistas semiestruturadas com tempo médio de 40 minutos cada, mediante concentração e paciência para "ouvir mais do que perguntar" (Lemgruber, 1983, p. 26).

Ainda, elaborou-se guia de perguntas para as diferentes populações, mas todas com abordagens sobre o tempo de vinculação/experiência com o sistema prisional, as expectativas e a compreensão sobre a pena de prisão, o encarceramento adaptado das mulheres e a pandemia. Ao final foram entrevistados: 9 servidores públicos da Superintendência dos Serviços Penitenciários (SUSEPE); 22 mulheres em situação de cárcere na PMI; 1 representante da delegacia de Polícia Civil; da Promotoria de Justiça; da Defensoria Pública e da Vara de Execução Penal (VEC). Todas as entrevistas observaram a concordância e assinatura de termo de consentimento, bem como sigilo dos nomes.

Quanto à população carcerária total da Penitenciária de Ijuí, importa destacar seu aumento em 60,1\% nos últimos oito anos, sendo a taxa de aprisionamento somente deste ano de 85,68 para cada 10 mil habitantes. Já a população feminina aumentou em 37,93\% para o mesmo período, isso considerando os esforços realizados pela comarca para evitar que o índice aumentasse. Essa população feminina é majoritariamente de residentes na cidade, jovens, brancas e negras em igual proporção, solteiras, mães, com ensino fundamental incompleto, recolhidas pelo envolvimento ou suposto envolvimento no tráfico de drogas.

\section{A (in)eficácia das Regras Limitativas de Manutenção e Decretação de Prisões no Contexto da Pandemia}

No panorama pandêmico o CNJ editou a importante Recomendação $\mathrm{n}^{\circ}$ 62, de 17 de março de 2020, que frisa a 
obrigação do Estado de assegurar o atendimento de saúde para pessoas privadas de liberdade, em respeito à dignidade, aos direitos humanos e às liberdades fundamentais previstos na Constituição Federal de 1988, dentre outros dispositivos legais e compromissos internacionais. Com 16 artigos a normativa trata de cinco pontos principais, são eles: (i) a redução do fluxo de ingresso no sistema prisional e socioeducativo; (ii) medidas de prevenção na realização de audiências judiciais nos fóruns; (iii) suspensão excepcional da audiência de custódia, mantida a análise de todas as prisões em flagrante realizadas; (iv) ação conjunta com os Executivos locais na elaboração de planos de contingência e (v) suporte aos planos de contingência deliberados pelas administrações penitenciárias dos estados em relação às visitas. Assim, ancorada nas finalidades de proteção à vida das pessoas privadas, e também de todos os servidores e agentes públicos, a adoção das diretrizes seria a garantia de continuidade da prestação jurisdicional.

Para o presente estudo são selecionadas as orientações dadas no âmbito do processo criminal ao/as magistrados/as com competência para a fase de conhecimento (Art. $4^{\circ}$ ) e de execução penal (Art. $5^{\circ}$ ). São diretrizes de revisão de prisões provisórias de gestantes, lactantes, mães e responsáveis de crianças de até doze anos ou outra pessoa que se enquadre no grupo de risco; daquelas que estão em estabelecimentos com ocupação superior à capacidade ou que disponham de instalações que favoreçam a propagação do vírus; das que tenham excedido noventa dias ou que estejam relacionadas a crimes sem violência. Ainda, a Recomendação prevê a máxima excepcionalidade de novas ordens de prisão preventiva. Já para as pessoas condenadas, a concessão de saída antecipada pelas mesmas condições postas à revisão das provisórias é medida que se impõe conjuntamente à concessão de prisão domiciliar em relação a todas as pessoas em cumprimento de pena nos regimes aberto e semiaberto.

Neste cenário, identifica-se que a Polícia Civil não tinha nenhuma orientação referente ao CNJ, nem mesmo conhecimento do formulário de identificação de fatores de risco para a Covid-19 elaborado pelo Conselho para as autoridades policiais. No curso da coleta de dados, a Promotoria de Justiça manifesta que a Recomendação não causou impacto para a desencarcerização de mulheres, nem de mulheres mães. Nas palavras da entrevistada:

"O que eu posso te dizer é que questão da prisão domiciliar pra quem tem filhos sob sua responsabilidade menores de doze anos... tem tido muita prisão domiciliar por este motivo. Isso eu posso te dizer. Não especificamente da Covid19."

Por sua vez, a Defensoria Pública explica que após a Recomendação procedeu um levantamento das condições de saúde das pessoas privadas de liberdade no âmbito de Ijuí, com pedido de emissão de atestados médicos pela Unidade Básica de Saúde Prisional. Houve um mutirão para pedidos de prisão domiciliar e, segundo informação, na PMI o "impacto ainda foi pouco, pouquíssimo". Na época da coleta de dados os atendimentos da Defensoria estavam suspensos e havia dificuldades de contato com os/as custodiados/as pela falta de estrutura tecnológica. Desse modo, uniam esforços para dar seguimento aos atendimentos da população carcerária por telefone ou por escrito.

Sobre a situação, a VEC afirma que a aplicação da Recomendação no quesito das prisões provisórias depende da análise do caso concreto, da mesma forma que as medidas alternativas à prisão. Sobre as medidas alternativas, o entrevistado desviou as perguntas utilizando o seguinte argumento:

"Isso é analisado caso a caso. É difícil. Hoje já se prende só quando é extremamente necessário".

Do diálogo sobre a Recomendação é possível concluir que a VEC compreende que são só orientações, que não há "vinculação". Mesmo que não tenha se manifestado contrário à Recomendação, a narrativa demonstra o apego aos argumentos formais (normas dispositivas e normas cogentes). Para melhor elucidação do posicionamento da VEC no âmbito da orientação de revisão das prisões provisórias que tenham excedido noventa dias, nos termos da orientação do CNJ, serve a Tabela 1 , 
abaixo apresentada. Para a sua construção foram comparadas as listas de mulheres encarceradas na PMI nos dias 13/12/2019 e 27/05/2020, marcando a data da prisão de cada uma delas para o cálculo de tempo de reclusão.

Tabela 1 - Prisões Provisórias

\begin{tabular}{|l|c|}
\hline Prisão provisória acima de 90 dias * & $\mathbf{n}(\%)$ \\
\hline Sim & $10(66,6)$ \\
\hline Não & $5(33,4)$ \\
\hline & \\
* Do total 4 estavam desde 13/12/2019 e 11 & \\
entraram até $27 / 05 / 2020$ & \\
\hline
\end{tabular}

Fonte: Autores (2020).

Em 27/05/2020 havia 15 mulheres encarceradas preventivamente, das quais 4 permaneciam nessa condição desde 13/12/2019. Das 11 mulheres que ingressaram na PMI após 13/12/2019, 3 foram encarceradas após a data de publicação da Recomendação do CNJ. Do total de 15, 5 mulheres estavam segregadas há mais de 90 dias. Em vista disso, mesmo que existam particularidades para decretação e a revisão das prisões, importa o fato de que nenhuma das presas provisórias da PMI foi liberada ou deixou de ser encarcerada em razão da pandemia, pelo menos até 27/05/2020. Não houve revisão das prisões, fato que também se torna relevante ao se considerar que a principal causa das prisões femininas é o tráfico de drogas, que envolve ilícitos comumente praticados sem violência ou grave ameaça.

As prisões por tráfico de drogas somam percentual expressivo entre a totalidade de mulheres segregadas na PMI em dezembro de 2019. Elas representam 73,9\%. Além disso, dentre as 22 entrevistadas, muitas são mães com problemas de saúde. A título de exemplo, uma das entrevistadas relata uma parada respiratória aguda em agosto de 2019, por bronquite asmática, situação que a transladou para internação durante três meses no Centro de Custódia Hospitalar Vila Nova, localizado em Porto Alegre, capital do RS. Com seríssimos problemas respiratórios mesmo aos 26 anos de idade veio de outro estado para o RS como tentativa de fuga do ex-marido que a perseguia, já que "nenhuma medida preventiva da Maria da Penha serviu".

Quanto ao contexto de pandemia, as mulheres encarceradas na PMI afirmam não saber até quando "vão segurar a cadeia". Alguns trechos:

"Ai essa pandemia... Sem poder ir pra íntima, numa relação, né? Um carinho... Mas tá louco! As mães sem ver os filhos, por favor!"

“Na cela deitada, eu pensava 'meu Deus vou me matar aqui, não aguento mais'. Porque eu já era sozinha, né? Em casa sozinha, eu morava sozinha, aí ali mais sozinha ainda num quadradinho daqueles, minha nossa senhora! Apavorada, eu mandei uma carta pra mãe: 'Não sei se eu aguento muito tempo, se não me tirarem daqui!' [...] Daí eu não sei nem se a mãe respondeu, não entregam, não mandam as coisas..."

"Não, daí veio o Natal, o juiz não me atendeu. Veio o Carnaval, o juiz não me atendeu. Daí veio essa doença aí não atendeu...".

Sobre os vínculos afetivos na PMI, algumas demonstram estar com os companheiros mais por comodidade, outras reclamam de ciúmes excessivos. Há também as que mantêm o vínculo por causa das sacolas que são entregues pelas famílias dos homens presos e assim podem "se apoiar". Nesse aspecto, alguns relacionamentos também iniciam na instituição, por trocas de bilhetes até a formalização da íntima. Contudo com a decretação de pandemia as próprias visitações entre presos na PMI foram suspensas. 


\section{As Sobrecargas Punitivas que Sofrem as Mulheres Privadas de Liberdade}

O Brasil é a terceira maior população carcerária do mundo, atrás dos Estados Unidos e China, e a quarta feminina, atrás da Rússia. A presente taxa de ocupação de vagas ultrapassa 170\% de sua capacidade (Prision, 2020). Os números crescem paralelamente à contínua expansão do poder punitivo, já que o sistema penal não logrou qualquer redução significativa no número de pessoas atrás das grades quando ultrapassou os muros das prisões (penas alternativas), nem sequer o reconhecimento da Suprema Corte do Estado de Coisas Inconstitucional do sistema penitenciário promoveu medidas desencarceradoras (Karam \& Darke, 2016).

Durante a pesquisa, a incongruência dos dados oficiais sobre as mulheres presas na PMI diante da realidade observada em campo permite indagar: elas existem? Porque algumas plataformas como o Geopresídios do CNJ apresentam a instituição somente como masculina. A dubiedade traz à tona um agravamento inerente à história das mulheres e do cárcere: a omissão. A falta de vagas em instituições prisionais decorre de uma mudança nos controles sociais lançados ao corpo feminino, que se concretizam no âmbito do controle penal (Miralles, 2015, p 219). Nesse sentido, o encarceramento para tratamento "terapêutico" em clínicas após ser enfrentado pela base reformista ocasionou a construção tardia de prisões femininas, sob a égide do “diferente, porém igual” (Davis \& Dent, 2013). Ainda, forjou que muitas sejam intituladas de mistas, como a PMI, pelas adaptações ilegais ocasionadas, por sua vez, pela necessidade de espaço ante a expansão do encarceramento de mulheres nos últimos anos no país.

Consequentemente, as celas e as condições estruturais constituem ponto sensível em relação à sobrecarga de punição vivida pelas mulheres na instituição prisional objeto deste estudo. Em oito celas para duas pessoas, quarenta estão distribuídas na PMI em condições sanitárias precárias. Sobre as celas:

“é muita mulher numa cela só... Nós tamo em 5 agora... saiu uma semana passada. Daí tem 2 na cama e 4 no chão com colchão, esses colchãozinho pequeninho..."

"Tô tendo que conviver com pessoas diferentes, cada um tem o seu crime, né? Então tipo, a convivência é tranquila, no respeito, né? Tem coisas que tu tem que aprender dentro da cela pra ter um bom convívio... Isso eu comecei a aprender, o respeito, né?"

Do total de 40 mulheres em situação de cárcere durante o período de coleta estima-se que 35\% têm até 29 anos; $50 \%$ são negras (pardas e pretas) e 50\% são brancas; 52,5 \% com ensino fundamental incompleto; 50\% não possuem relacionamento; $85 \%$ são mães, com média de 2 filhos. Na PMI coexistem linhas que demarcam aqueles/as que se ajustam e os que não se ajustam às regras disciplinares, mas também possui linhas orientadas pela concepção dualista de ser homem e de ser mulher que define os espaços que serão ocupados (Colares \& Chies, 2010).

As mulheres estão privadas de liberdade na PMI, mas também do acesso integral a dependências como o pátio grande, que também é chamado na instituição de pátio dos homens. Em um dia comum o pátio grande é movimentado, são muitos homens dispostos das mais diversas formas com os mais diversos sons. Na oportunidade da pesquisa de campo, alguns jogavam bola, outros faziam tatuagens, pintavam os cabelos, jogavam baralho, se exercitavam, discutiam, dançavam, rezavam. Já o pátio das mulheres é marcado pelo silêncio e pela divisão. Vê-se uma ou outra sentada conversando, às vezes caminhando de um lado para o outro. A diferença entre os pátios não está só na estrutura e na configuração de seu uso, mas também na sua disponibilidade. Se os dias de visita no pátio das mulheres ocorrem nas quartas-feiras e sábados e nas quintas-feiras e domingos, o pátio é ofertado apenas três vezes na semana por duas horas enquanto para os homens é ofertado todos os dias. Durante a pandemia as visitas estavam suspensas, mas só o uso do pátio permanecia ativo apenas pelos homens enquanto as mulheres preferiam permanecer nas celas. Sobre as diferenças entre as visitas de homens e de mulheres, alguns servidores da área socioassistencial da SUSEPE relatam que: 
"As mulheres quando têm os homens presos sempre vêm fazer a visita e se elas saem de verdade, são raríssimos os homens que vêm visitá-las."

“Tem poucas visitas. Quase nada. Quem vem ou é pai, ou é mãe. Filhos se são maiores. Marido se tem, quando vem é uma vez, duas vezes. Só no começo. Não acompanham. Ao contrário dos presos homens."

O improviso existente na PMI há quase vinte anos foi objeto de questionamento tanto para agentes públicos quanto para as mulheres encarceradas. Os primeiros não possuem um posicionamento unificado. Alguns relatam que é melhor trabalhar com 800 homens do que com as mulheres, já que, segundo uma agente da SUSEPE entrevistada:

"Elas brigam por nada, agitam por fofoca, por esmalte, sem falar da questão pré-menstrual e das que estão com filhos doentes e querem informações chamando o tempo inteiro."

Outros policiais penais disseram que a situação das mulheres é uma "bomba", que está totalmente irregular. Um deles afirma que qualquer coisa que acontecer com essas mulheres será responsabilidade do estado, que elas estão presas na frente de uma galeria que tem mais de cem homens. Um dos relatos de um agente policial, com mais de vinte anos de atuação no sistema prisional, que já viu situações em instituições mistas, onde 20 mulheres ocupavam celas destinadas para até seis, chama a atenção. O servidor explica que sua experiência também lhe permitiu compreender que as mulheres, para além das necessidades básicas distintas, como um vaso na cela, têm outras formas de resoluções de conflitos.

Embora existam diferentes opiniões, a realidade é que as mulheres encarceradas estão submetidas a um tratamento institucional que desconhece peculiaridades do gênero feminino. Diferente da SUSEPE, as mulheres encarceradas não divergem e expressam a necessidade de um local mais adequado quando questionadas sobre as sobrecargas. Uma delas expressa:

"Olha, ia ser bom, né? Porque pelo menos é uma coisa para entreter, né? Porque a gente não tem o que fazer na cela... Lá os cara tem tudo...E aqui eles não deixam nem a gente ter uma bola pra jogar... No caso aqui tem que ficar caminhando, né? Porque é a única coisa que tu faz é caminhar porque é um pátio pequeno, né?"

Sobre esse encarceramento adaptado, a VEC diz que a falta de estrutura é um problema de todo o interior do RS, que "é esquecido quanto a presídios femininos, como se não tivéssemos mulher presa". Essa ideia de improvisação faz compreender que "a estrutura estatal é central para conhecer o caráter profundamente influenciado pelo gênero da punição ao mesmo tempo reflete e consolida ainda mais a estrutura de gênero da sociedade como um todo“(Davis, 2018, p. 66). De tal forma que estar na prisão implica dificuldades e restrições, mas ser mulher e estar aprisionada incute um status de transgressora da ordem da sociedade e da família. A privação de liberdade, comum a todos os prisioneiros, é "para as mulheres o sinônimo de uma vigilância rígida para protegê-las contra elas mesmas, o que explica por que a direção de uma prisão de mulheres se sente investida de uma missão moral" (Lemgruber, 1983, p. 86).

Logo, a unidade prisional masculinamente mista aporta vantagens ao homem preso, enquanto os interesses da mulher são deixados totalmente de lado (Miralles, 2015). O tempo dentro das celas expressa algumas diferenças, pois as mulheres raramente saem já que o pequeno pátio que a elas está destinado acaba sendo local de intriga. Algumas alegam que para não se incomodar ficam mais de 15 dias sem sol, que permanecem nas celas cujo espaço compartilhado se torna um mundo. É lá que dormem, comem, fazem a higiene pessoal. Elas ordenam a cela conforme as suas necessidades, há pertences pendurados por todos os lados, na tentativa de aproximar a precariedade do local ao maior aconchego possível mesmo na presença de ratos e baratas, da umidade, dos colchões finos. As afinidades são definidas pelos laços já havidos antes da prisão, pelas facções e também pelo tipo penal. Nas celas lotadas os lugares são definidos por tempo de casa, assim quem chega por último dorme perto da patente da cela, chamada de "bói". 
A dupla ordem de punição, então, se acentua em um sistema jurídico que não só executa a criminalização, mas mantém restrições no âmbito carcerário, como no indeferimento de visitas e na falta de revisão das prisões mesmo em um contexto de pandemia. Compreendidas na totalidade, as sobrecargas punitivas vividas também reforçam as dificuldades que já enfrentavam. Exploradas, oprimidas, foram enclausuradas em uma instituição masculinamente mista na qual a privação tornase praticamente absoluta, o espaço de homens para homens restringe às mulheres a circulação, a vestimenta e o trabalho disponível.

\section{Considerações Finais}

A análise da normativa produzida pelo CNJ para o enfrentamento da chamada crise sanitária valida a leitura de que "as declarações formais de direitos, gerais e abstratas, são de pouco valor, correspondem à ideologia do sistema e encobrem desigualdades, dominação e opressão, através de representações ilusórias" (Fragoso, 1980, p. 8). Para além, a realidade encontrada "não apenas demonstra que os métodos tradicionais de intervenção penal são ineficazes, como evidencia que são inatingíveis, ou seja, não cumprem e sequer poderiam cumprir as finalidades declaradas" (Carvalho, 2019, p. 26).

Conduzida pela perspectiva interseccional, a pesquisa considera o encarceramento uma problemática sociológica para a qual a articulação das relações é concreta e suas transformações são históricas. Desse modo, as propriedades dos agentes sociais não são compreendidas em termos de vantagens ou desvantagens, mas, sim, em termos de dominação (Vigoya, 2016). No Brasil, as diferenças determinam acessos desequilibrados constituindo desigualdades que estruturam todas as relações de classe, raça (Mota, 2020) e também os índices de criminalização e aprisionamento.

Nesse sentido, durante a pandemia, o Estado assume, sobretudo, papéis de eficiência e intransigência, enquanto busca satisfazer a sociedade em nome da defesa social, visto que liberar presos, além de colocar em risco a sociedade sobrecarregaria ainda mais o sistema de saúde. Ou seja, o discurso da intransigência assume objetivos econômicos, "é a gestão de uma permanente população perigosa, pelo menor preço possível" (Dieter, 2013, p. 100). Nesse contexto, o papel do discurso de eficiência é o reflexo da sociedade do controle e do desempenho, na qual a lógica do corpo moldado como disciplinado para a melhor execução do trabalho é a matriz, as prisões são os espaços da massa dos indesejados (Borges, 2019).

Dessa maneira, todo o encarceramento é parte da instrumentalização do sistema penal, que simbolicamente cumpre suas funções declaradas, já que, de fato, incidem negativamente na sociedade, não resolvendo a criminalidade, mas mantendo as categorias dominadas pela classe, pela raça e pelo gênero. Sequencialmente, a pesquisa de campo realizada evidenciou que a Pandemia de Covid-19 reconfigurou a administração prisional, aprofundando as restrições de direitos e, consequentemente, as sobrecargas vividas pelas mulheres em situação de cárcere. Ainda, possível constatar a peculiaridade de que muitas mulheres presas na PMI possuem seus companheiros presos, que também realizam vigilância sobre os seus corpos. O encarceramento é, portanto, inadequado. Assim, a interseção de criminalidade e sexualidade, que possui dimensão histórica, está reproduzida na prática das prisões femininas e mistas.

Também no âmbito de pesquisa, identifica-se que mesmo em uma pandemia, na qual o aprisionamento "pode ser equivalente a uma sentença de morte" (Davis, Klein, 2020, p. 11), a atuação do Poder Judiciário é marcada por restrições de direitos e pelo aprofundamento das sobrecargas punitivas. Pois, para além das restrições impostas, a falta de observância das orientações do CNJ pelos/as magistrados/as aprofunda essas restrições. O levantamento de dados analisando a aplicabilidade da Recomendação no âmbito do aprisionamento provisório de mulheres na PMI conduz a reflexões acerca da contrariedade de setores do próprio sistema de justiça, que, parece, mais afasta os direitos fundamentais do que os aplica. Sem desconsiderar as particularidades para a adoção das medidas do CNJ, a realidade coletada em campo mostra que na PMI a eficácia da Recomendação é praticamente nula.

Identificaram-se, ainda, as desvantagens das mulheres em relação a alguns direitos na PMI, como, por exemplo, o uso 
do pátio. Essas restrições aportam a existente sobrecarga de punição, que se estende à falta de atividade física organizada, favorecendo o sedentarismo e causando danos, muitas vezes irreversíveis, à saúde física e mental. Assim, as necessidades das mulheres presas, a partir de suas vivências em sociedade, cumprem o roteiro para o tratamento penal, que não observa os direitos mais básicos e (re)produz as sobrecargas. Assim, mediante realização de pesquisa empírica, o estudo demonstrou que prisões adaptadas desconsideram peculiaridades específicas das populações femininas que são encarceradas e que a permanência nas condições ilegais de encarceramento apesar da crise está legitimada por decisões judiciais.

À luz de conclusão, a realidade do encarceramento feminino é a realidade da sobrecarga punitiva, marcada e reforçada por concepções moralizantes dos operadores do sistema de justiça criminal e, ainda, aprofundada em tempos pandêmicos. De tal maneira, a experiência teórico-prática aqui apresentada reforça a necessidade de intervenções acadêmicas no sistema prisional para acompanhar sua dinâmica, principalmente quando há mais um motivo para blindar a vioência institucional, como é o caso de uma crise sanitária. Logo, futuramente, nova análise será necessária na PMI para que seja possível identificar a continuidade da administração da pandemia na instituição.

\section{Referências}

Aniyar de Castro, L. (2005). Criminologia da libertação. Revan.

Andrade, V. (2009) Flagrando a ambiguidade da dogmática penal com a lupa criminológica: que garantismo é possível do compasso criminologia - penalismo crítico? Revista Sequência. 30(59), 161-92.https://doi.org/10.5007/2177-7055.2009v30n59p161

Borges, J. (2019). Encarceramento em massa. Polén.

Campos, C. A. de A. (2016). Estado de Coisas Inconstitucional. JusPodivm.

Carvalho, S. (2019). Erich Fromm e a crítica da pena: aproximações entre psicanálise e criminologia desde a teoria crítica da sociedade. Revista Eletrônica do Curso de Direito da UFSM, 14(3), 1-40. https://doi.org/10.5902/1981369437766-

Chies, L. A. B. (2008). Gênero, criminalização, punição e "sistema de justiça criminal”: Um olhar sobre as sobrecargas punitivas e as dominações do masculino. Revista de Estudos Criminais, 8 (28), 81-105.

Colares, L. B. C., \& Chies, L.A.B. (2010). Mulheres nas so(m)bras: invisibilidade, reciclagem e dominação viril em presídios masculinamente mistos. Revista Estudos Feministas, 18(2), 407-423. https://doi.org/10.1590/S0104-026X2010000200007

Conselho Nacional de Justiça. Recomendação $n^{\circ} 62$ de 17/03/2020. https://atos.cnj.jus.br/atos/detalhar/3246

Conselho Nacional de Justiça. Formulário de identificação de fatores de risco para a Covid-19 pela Autoridade Policial. https://www.cnj.jus.br/wpcontent/uploads/2020/05/Formul\%C3\%A1rio-de-identifica\%C3\%A7\%C3\%A3o-de-fatores-de-risco-para-a-Covid-19-pela-Autoridade-Policial.pdf.

Davis, A. (2018). Estarão as prisões obsoletas? Difel.

Davis, A., \& Dent, G. (2013) A prisão como fronteira: uma conversa sobre gênero, globalização e punição. Revista Estudos Feministas, 11(2): 523-531. https://doi.org/10.1590/S0104-026X2003000200011

Davis, A. \& Klein, N. (2020) Construindo Movimentos: uma conversa em tempos de pandemia. Boitempo.

Dieter, M. S. (2013). Política criminal atuarial: a criminologia do fim da história. Revan.

Federici, S. (2017). O Calibã e a Bruxa: mulheres, corpo e acumulação primitiva. Elefante.

Fragoso H. C. (1980) Direito dos Presos: os problemas de um mundo sem lei. In: Fragoso, H.C., Catão, Y. \& Sussekind, E. Direito dos Presos. Forense.

Karam, M. L., \& Darke, S. (2016). Prisões latino-americanas. https://emporiododireito.com.br/leitura/prisoes-latino-americanas-1508702837

Lemgruber, J. (1983). Cemitério dos Vivos: Análise sociológica de uma prisão de mulheres. Achiamé.

Miralles, T. (2015). O Controle Formal: O Cárcere. In: Bergalli, R. \& Ramirez, J. B. O Pensamento Criminológico - II. Estado e Controle. Rio de Janeiro: Revan.

Ribeiro. D. (2017). Feminismo negro: para além de um discurso identitário. https://revistacult.uol.com.br/home/feminismo-negro-para-alem-de-um-discursoidentitario/

Weigert, M., \& Carvalho, S. (2020). Criminologia Feminista com Criminologia Crítica: perspectivas teóricas e teses convergentes / Feminist Criminology allied to Critical Criminology: theoretical perspectives and convergent theses. Revista Direito e Práxis, 11(3), 1783-1814. https://doi.org/10.1590/2179$8966 / 2019 / 38240$ 